\title{
Bioactivities of Artocarpus chaplasha Roxb. and Bougainvillea spectabillis Willd.
}

\author{
Farjana Chowdhury ${ }^{1}$, Senjuti Pal ${ }^{1}$, Tasnuva Sharmin ${ }^{1}$, Ridwan Bin Rashid ${ }^{2}$, Md. Al Amin \\ Sikder ${ }^{3}$, Shaila Kabir ${ }^{3}$, Mohammad S. Rahman ${ }^{3}$ and Mohammad A. Rashid ${ }^{3}$ \\ ${ }^{1}$ Department of Pharmacy, State University of Bangladesh, Dhaka-1205, Bangladesh \\ ${ }^{2}$ Department of Microbiology, University of Dhaka, Dhaka-1000, Bangladesh \\ ${ }^{3}$ Phytochemical Research Laboratory, Department of Pharmaceutical Chemistry, Faculty of Pharmacy, \\ University of Dhaka, Dhaka-1000, Bangladesh
}

\begin{abstract}
The methanol extracts of leaf of Artocarpus chaplasha Roxb. and Bougainvillea spectabillis Willd. as well as their petroleum ether, carbon tetrachloride, chloroform and aqueous soluble partitionates were subjected to screenings for antioxidant, cytotoxic, thrombolytic, membrane stabilizing and antimicrobial activities. The antioxidant potential was evaluated by 1,1-diphenyl-2-picrylhydrazyl (DPPH) and FolinCiocalteau reagent using butylated hydroxytolune (BHT) and ascorbic acid as standards. The aqueous soluble fraction of the crude methanol extract of $A$. chaplasha and the methanolic crude extract of $B$. spectabillis demonstrated the highest free radical scavenging activity with the $\mathrm{IC}_{50}$ of $15.60 \pm 0.27 \mu \mathrm{g} / \mathrm{ml}$ and $18.33 \pm 0.17 \mu \mathrm{g} / \mathrm{ml}$, which could be correlated to their total phenolic content of $61.26 \pm 0.23$ and $50.00 \pm 0.19 \mathrm{mg}$ of GAE/gm of extractive, respectively. Different extractives of $A$. chaplasha and $B$. spectabillis showed clot lysis activity ranging from $2.56 \pm 0.68 \%$ to $17.07 \pm 0.23 \%$ and $2.24 \pm 0.71 \%$ to $17.59 \pm 0.74 \%$ as compared to $66.77 \%$ and $3.791 \%$ produced by the standard streptokinase and water, respectively. In hypotonic solution and heat induced conditions, the crude extract of $A$. chaplasha inhibited the haemolysis of human erythrocyte by $41.96 \pm 0.87 \%$ and $40.00 \pm 0.78 \%$, while the carbon tetrachloride soluble fraction of methanol extract of $B$. spectabillis inhibited haemolysis by $65.68 \pm 0.36 \%$ and $35.62 \pm 0.82 \%$, respectively. Here, acetyl salicylic acid $(0.1 \mathrm{mg} / \mathrm{ml})$ was used as reference showing $72.79 \%$ and $42.12 \%$ of haemolysis of RBCs in hypotonic and heat induced conditions, respectively. Among the extractives of both plants, the crude methanol extract of $A$. chaplasha and the chloroform soluble fraction of $B$. spectabillis extract revealed mild to moderate antimicrobial activity with zone of inhibition ranging from with 7.0 to $13.0 \mathrm{~mm}$. The general toxicity was determined by brine shrimp lethality bioassay where the pet-ether soluble fraction of $A$. chaplasha $\left(\mathrm{LC}_{50} 0.781 \pm 0.36 \mu \mathrm{g} / \mathrm{ml}\right)$ and the aqueous soluble partitionate of $B$. spectabillis $\left(\mathrm{LC}_{50} 1.28 \pm 0.57 \mu \mathrm{g} / \mathrm{ml}\right)$ suggested the presence of considerable bioactive principles.
\end{abstract}

Key words: Artocarpus chaplasha, Bougainvillea spectabillis, antioxidant, DPPH, thrombolytic, membrane stabilizing, antimicrobial, cytotoxicity.

\section{Introduction}

Natural products have contributed a lot for developing new drug molecules. Until today, medicinal chemists look around plants, herbs, microorganisms, marine resources etc. to incorporate new lead compounds. Bangladesh is blessed with numerous medicinal plants used for traditional healing (Butler, 2005; Gan et al., 2010). Very few of them have been scientifically evaluated for exploring their chemical constituents and biological activities. In the process of our continuous study with medicinal plants of Bangladesh (Sikder et al., 2011; Kaisar et al., 2011), we have investigated Artocarpus chaplasha Roxb. and Bougainvillea spectabillis Willd. in the current study.

A. chaplasha Roxb. (Synonyms: A. chama Buch.Ham., Urostigma chrysophthalmum Miq.; Bengali name: Chapalish) belongs to the family Moraceae. The plant is native to northeastern India, lower Myanmar and the Andaman and Nicobar Islands. It is also available in sub-Himalayan tract, Nepal, and other parts of East Asia (Flora of China, 2012).

B. spectabillis Willd. (Synonyms: B. bracteata Pers., B. brasiliensis Raeusch; Bengali name: Bagan bilash) belongs to the family Nyctaginaceae. It is 
native to South America and is considered as a popular ornamental plant in the Philippines. In Bangladesh, the plant is widely distributed. The root of the plant possesses hypoglycaemic (Jawla, 2011) and antihyperlipidemic properties (Saikia and Lama, 2011)

In this investigation, the methanol extracts of leaves of A. chaplasha and $B$. spectabillis growing in Bangladesh as well as their organic and aqueous soluble fractions were studied for assessing the antioxidant, cytotoxic, thrombolytic, membrane stabilizing and antimicrobial activities and, we herein, report the results of our preliminary studies for the first time.

\section{Materials and Methods}

Collection of plant materials and extraction: The leaves of A. chaplasha were collected in March 2012 from Mirpur Botanical Garden, Dhaka and a voucher specimen (DACB-37786) for this collection has been deposited in Bangladesh National Herberium. On the other hand, the leaves of $B$. spectabillis were collected in April 2012 from Baldha Garden, Dhaka and a voucher specimen (DUSH-3630) has been deposited in Salar Khan Herbarium, Department of Botany, and University of Dhaka.

The collected plant materials were cleaned, sun dried and pulverized. The powdered materials (500 g each) of both the plants were separately soaked in 2.0 liter of methanol at room temperature for 7 days. The extracts were filtered through fresh cotton bed and finally with Whatman filter paper number 1 and concentrated with a rotary evaporator at reduced temperature and pressure. An aliquot (5 g) of each of the concentrated methanol extract was fractionated by the modified Kupchan partitioning method (Van Wagenen et al., 1993) and the resultant partitionates were evaporated to dryness with a rotary evaporator to yield petroleum ether (PESF), carbon tetrachloride (CTCSF), chloroform (CSF) and aqueous (AQSF) soluble materials (Table 1). The residues were then stored in a refrigerator until further use.

\section{Evaluation of Biological Activities}

Total phenolic content: The total phenolic content of the extractives were determined with FolinCiocalteau reagent by using the method developed by Harbertson and Spayd (2006).
$D P P H$ free radical scavenging assay: Following the method developed by Brand-Williams et al. (1995), the antioxidant activity of the test samples was assessed through the scavenging of the stable 1,1-diphenyl-2picrylhydrazyl (DPPH) free radical by using synthetic antioxidants, butylated hydroxytoluene (BHT) and ascorbic acid as positive controls.

Table 1. Kupchan partitioning of $A$. chaplasha and $B$. spectabillis

\begin{tabular}{ccc}
\hline $\begin{array}{c}\text { Fractions/crude } \\
\text { extract }\end{array}$ & A. chaplasha $(\mathrm{g})$ & $\begin{array}{c}\text { B. spectabillis } \\
\text { (g) }\end{array}$ \\
\hline Me & 5.0 & 5.0 \\
PESF & 1.0 & 1.5 \\
CTCSF & 1.5 & 1.2 \\
CSF & 1.0 & 0.5 \\
AQSF & 0.5 & 1.0 \\
\hline
\end{tabular}

Thrombolytic activity: The thrombolytic activity was determined by the method developed Prasad et al. (2006) where streptokinase (SK) was used as the positive control.

Membrane stabilizing activity: The membrane stabilizing activity of the extractives was assessed through hypotonic solution- and heat-induced hemolysis of human erythrocytes by following standard method (Omale and Okafor, 2008).

Antimicrobial screening: Antimicrobial activity was determined by the commonly used disc diffusion method (Bauer et al., 1966).

Brine shrimp lethality bioassay: This technique was applied for determination of the general toxic properties of the DMSO solutions of plant extractives against Artemia salina in a single day in vivo assay (Meyer et al., 1982). Vincristine sulphate was used as positive control.

Statistical analysis: For all bioassays, three replicates of each sample were used for statistical analysis and the values are reported as mean \pm SD.

\section{Results and Discussion}

The crude extracts of leaves of $A$. chaplasha and $B$. spectabillis as well as their Kupchan partitionates were subjected to assays for total phenolic content, free radical scavenging, cytotoxic, thrombolytic, membrane stabilizing and antimicrobial activities. 
Total phenolic content of the extractives: The total phenolic content of the samples of A. chaplasha were found in the range of 7.66 to $85.77 \mathrm{mg}$ of GAE/gm of sample. The highest amount of phenolic compounds (85.77 $\pm 0.84 \mathrm{mg}$ of $\mathrm{GAE} / \mathrm{gm}$ of extractive) was observed in the petroleum ether soluble fraction. Among the samples of $B$. spectabillis, the total phenolic content was found in the range of 2.31 to $50.00 \mathrm{mg}$ of GAE/gm of dried extract while the highest amount of TPC (50.00 $\pm 0.19 \mathrm{mg}$ of GAE/gm of extractive) was found in the petroleum ether soluble fraction (Table 2).
Free radical scavenging activity of the extractives: In the DPPH free radical scavenging assay, the aqueous soluble fraction of crude methanol extract of leaves of A. chaplasha revealed maximum free radical scavenging activity $\left(\mathrm{IC}_{50}=15.60 \pm 0.27 \mu \mathrm{g} / \mathrm{ml}\right)$ when compared to ascorbic acid $\left(\mathrm{IC}_{50}=5.8 \pm 0.21 \mu \mathrm{g} / \mathrm{ml}\right.$ ). Among the test samples of $B$. spectabillis, the crude extract demonstrated the highest free radical scavenging activity $\left(\mathrm{IC}_{50}=18.33 \pm 0.17 \mu \mathrm{g} / \mathrm{ml}\right.$ ) (Table 2 ).

Table 2. Total phenolic content, cytotoxic, and free radical scavenging activity of $A$. chaplasha and $B$. spectabilis.

\begin{tabular}{|c|c|c|c|c|}
\hline Plants & $\begin{array}{l}\text { Samples/ } \\
\text { Standards }\end{array}$ & $\begin{array}{c}\text { Total phenolic content } \\
\text { (mg of GAE/gm of } \\
\text { extract) }\end{array}$ & $\begin{array}{c}\text { DPPH Free radical } \\
\text { scavenging activity } \\
\left(\mathrm{IC}_{50} \mu \mathrm{g} / \mathrm{ml}\right)\end{array}$ & $\begin{array}{l}\text { Cytotoxic activity } \\
\left.\text { (LC } \mathrm{L}_{50} \mu \mathrm{g} / \mathrm{ml}\right)\end{array}$ \\
\hline \multirow[t]{5}{*}{ A. chaplasha } & $\mathrm{ME}$ & $30.15 \pm 0.84$ & $15.70 \pm 0.21$ & $1.960 \pm 0.15$ \\
\hline & PESF & $85.77 \pm 0.84$ & $31.20 \pm 0.53$ & $0.781 \pm 0.36$ \\
\hline & CTCSF & $39.78 \pm 0.84$ & $62.50 \pm 0.81$ & $9.116 \pm 0.74$ \\
\hline & CSF & $7.66 \pm 0.26$ & $31.20 \pm 0.43$ & $24.56 \pm 0.42$ \\
\hline & AQSF & $61.26 \pm 0.23$ & $15.60 \pm 0.27$ & $6.416 \pm 0.22$ \\
\hline \multirow[t]{8}{*}{ B. spectabillis } & $\mathrm{ME}$ & $50.00 \pm 0.19$ & $18.33 \pm 0.17$ & $3.27 \pm 0.28$ \\
\hline & PESF & $41.81 \pm 0.48$ & $19.76 \pm 0.84$ & $4.57 \pm 0.52$ \\
\hline & CTCSF & $2.87 \pm 0.56$ & $44.74 \pm 0.23$ & $4.78 \pm 0.37$ \\
\hline & CSF & $11.37 \pm 0.11$ & $49.46 \pm 0.45$ & $5.13 \pm 0.39$ \\
\hline & AQSF & $2.31 \pm 0.87$ & $22.82 \pm 0.88$ & $1.28 \pm 0.57$ \\
\hline & VS & - & - & 0.451 \\
\hline & $\mathrm{BHT}$ & - & $27.5 \pm 0.54$ & - \\
\hline & Ascorbic acid & - & $5.8 \pm 0.21$ & - \\
\hline
\end{tabular}

The average values of three calculations are presented as mean \pm S.D.; BHT= Butylated hydroxytolune; VS= Vincristine sulfate; $\mathrm{ME}=$ Methanolic crude extract; $\mathrm{PESF}=$ Petroleum ether soluble fraction; $\mathrm{CTCSF}=$ Carbon tetrachloride soluble fraction; $\mathrm{CSF}=$ Chloroform soluble fraction; AQSF= Aqueous soluble fraction.

Thrombolytic activity: In order to identify the drugs with the ability to promote lysis of blood clot from natural resources, the extractives of $A$. chaplasha and $B$. spectabillis were assessed for thrombolytic activity and the results are presented in Table 3. Addition of $100 \mu \mathrm{l}$ SK, a positive control (30,000 I.U.) to the clots of human blood and subsequent incubation for 90 minutes at $37^{\circ} \mathrm{C}$ showed $66.77 \%$ lysis of clot. On the other hand, distilled water when treated as negative control, revealed a negligible lysis of clot (3.79\%). In this study, different extractives of $A$. chaplasha and B. spectabillis demonstrated poor clot lysis ranging from $2.56 \%$ to $17.07 \%$ and $2.24 \%$ to $17.59 \%$, respectively. The chloroform soluble fraction of the methanol extract of A. chaplasha and aqueous soluble fraction of the crude extract of $B$. spectabillis showed $17.07 \pm 0.23 \%$ and $17.59 \pm 0.74 \%$ clot lysis, respectively (Table 3 ).
Table 3. Thrombolytic activity of $A$. chaplasha and $B$. spectabillis extractives.

\begin{tabular}{lcc}
\hline \multirow{2}{*}{ Sample } & \multicolumn{2}{c}{ \% Of lysis of RBC } \\
\cline { 2 - 3 } & A. chaplasha & B. spectabillis \\
\hline ME & $2.77 \pm 0.54$ & $8.62 \pm 0.18$ \\
PESF & $5.55 \pm 0.39$ & $11.50 \pm 0.24$ \\
CTCSF & $13.79 \pm 0.48$ & $2.24 \pm 0.71$ \\
CSF & $17.07 \pm 0.23$ & $6.01 \pm 0.29$ \\
AQSF & $2.56 \pm 0.68$ & $17.59 \pm 0.74$ \\
Water & & $3.79 \pm 0.55$ \\
Streptokinase & & $66.77 \pm 1.08$ \\
\hline
\end{tabular}

Membrane stabilizing activity of the extractives: The membrane stabilizing activity of $A$. chaplasha and $B$. spectabillis extractives was also determined. All the extractives significantly protected the lysis of human erythrocyte membrane induced by hypotonic solution and heat, as compared to the standard acetyl salicylic acid. In hypotonic solution and heat induced conditions, 
the crude methanol extract of $A$. chaplasha inhibited $41.96 \pm 0.87 \%$ and $40.00 \pm 0.78 \%$ haemolysis of RBCs, respectively as compared to $72.79 \%$ and $42.12 \%$ inhibition by acetyl salicylic acid $(0.10 \mathrm{mg} / \mathrm{ml})$, respectively (Table 4). The carbon tetrachloride soluble fraction of methanol extract of $B$. spectabillis revealed $65.68 \pm 0.36 \%$ and $35.62 \pm 0.82 \%$ inhibition of hypotonic solution and heat induced haemolysis, respectively (Table 4).

Table 4. Percentage inhibition of hypotonic solution- and heat-induced hemolysis of erythrocyte membrane by $A$. chaplasha and $B$. spectabillis extractives

\begin{tabular}{|c|c|c|c|c|}
\hline \multirow{3}{*}{ Sample } & \multicolumn{4}{|c|}{ \% Inhibition of haemolysis } \\
\hline & \multicolumn{2}{|c|}{ A. chaplasha } & \multicolumn{2}{|c|}{ B. spectabillis } \\
\hline & $\begin{array}{l}\text { Hyponotic solution } \\
\text { induced }\end{array}$ & Heat induced & $\begin{array}{l}\text { Hyponotic solution } \\
\text { induced }\end{array}$ & Heat induced \\
\hline $\mathrm{ME}$ & $41.96 \pm 0.87$ & $40.00 \pm 0.78$ & $9.5 \pm 0.08$ & $20.92 \pm 0.84$ \\
\hline AQSF & $32.16 \pm 0.09$ & $27.82 \pm 0.25$ & $20.22 \pm 0.19$ & $22.08 \pm 0.21$ \\
\hline CSF & $34.60 \pm 0.27$ & $30.46 \pm 0.14$ & $27.94 \pm 0.54$ & $29.10 \pm 0.64$ \\
\hline CTCSF & $40.00 \pm 0.65$ & $27.58 \pm 0.88$ & $65.68 \pm 0.36$ & $35.62 \pm 0.82$ \\
\hline PESF & $32.15 \pm 0.81$ & $31.70 \pm 0.57$ & $61.86 \pm 0.68$ & $17.25 \pm 0.05$ \\
\hline ASA & $72.79 \pm 0.47$ & $42.12 \pm 0.23$ & $72.79 \pm 0.47$ & $42.12 \pm 0.23$ \\
\hline
\end{tabular}

ASA= Acetyl salicylic acid.

Table 5. Antimicrobial activity of A. chaplasha.

\begin{tabular}{lcccc}
\hline Test microorganisms & \multicolumn{4}{c}{ Diameter of zone of inhibition (mm) } \\
\cline { 2 - 5 } & ME & PESF & CTCSF & Ciprofloxacin \\
\hline Bacillus cereus & $9.0 \pm 0.39$ & - & - & $45 \pm 2.01$ \\
B. megaterium & - & - & - & $42 \pm 1.17$ \\
B. subtilis & $7.0 \pm 0.27$ & $7.0 \pm 0.45$ & - & $42 \pm 0.73$ \\
Staphylococcus aureus & $8.0 \pm 0.33$ & - & $8.0 \pm 0.38$ & $42 \pm 0.23$ \\
Sarcina lutea & $8.0 \pm 0.18$ & $7.0 \pm 0.30$ & $10.0 \pm 0.04$ & $42 \pm 0.56$ \\
Escherichia coli & - & - & - & $42 \pm 0.43$ \\
Pseudomonas aeruginosa & - & - & - & $42 \pm 1.11$ \\
Salmonella Typhi & $8.0 \pm 0.34$ & - & - & $45 \pm 0.73$ \\
S. Paratyphi & $8.0 \pm 0.68$ & - & - & $47 \pm 2.33$ \\
Shigella boydii & $8.0 \pm 0.82$ & - & - & $34 \pm 0.58$ \\
Sh. dysenteriae & $8.0 \pm 0.35$ & $8.0 \pm 1.03$ & $13.0 \pm 0.43$ & $42 \pm 0.22$ \\
Vibrio mimicus & $8.0 \pm 0.67$ & $9.0 \pm 0.83$ & - & $40 \pm 0.45$ \\
V. parahaemolyticus & - & - & $8.0 \pm 0.69$ & $35 \pm 0.44$ \\
Saccharomyces cerevisiae & - & - & - & $38 \pm 0.49$ \\
Candida albicans & $8.0 \pm 0.28$ & - & - & $37 \pm 0.33$ \\
Aspergillus niger & - & $7.0 \pm 0.58$ & - & $38 \pm 0.11$ \\
\hline
\end{tabular}

Antimicrobial activity: The extractives of $A$. chaplasha and $B$. spectabillis were also subjected to screenings for in vitro antimicrobial activity against five gram positive and eight gram negative bacteria and three fungi at $400 \mu \mathrm{g} /$ disc. The test samples of $A$. chaplasha revealed mild to moderate inhibitory activity against the tested pathogens having zone of inhibition within the range of 7.0 to $13.0 \mathrm{~mm}$. The carbon tetrachloride soluble fraction of $A$. chaplasha demonstrated $13 \pm 0.43 \mathrm{~mm}$ zone of inhibition against Shigella dysenteriae (Table 5). Among the samples of $B$. spectabillis, only the chloroform soluble fraction revealed weak antimicrobial activity as evident from smaller zone of inhibition (8.0 to $11.0 \mathrm{~mm}$ ) against all the tested microorganisms. This fraction also showed $11.0 \pm 0.80$ and $11.0 \pm 0.43 \mathrm{~mm}$ zones of inhibition 
against Pseudomonas aeruginosa and Bacillus cereus, respectively (Table 6). The inhibitory activity of the extractives was compared with standard antimicrobial agent, ciprofloxacin.

Table 6. Antimicrobial activity of $B$. spectabillis.

\begin{tabular}{lcc}
\hline \multirow{2}{*}{ Test microorganisms } & \multicolumn{2}{c}{$\begin{array}{c}\text { Diameter of zone of inhibition } \\
\text { (mm) }\end{array}$} \\
\cline { 2 - 3 } & CSF & Ciprofloxacin \\
\hline Bacillus cereus & $11.0 \pm 0.43$ & $45.0 \pm 2.01$ \\
B. megaterium & $9.0 \pm 0.28$ & $42.0 \pm 1.17$ \\
B. subtilis & $9.0 \pm 0.62$ & $42.0 \pm 0.73$ \\
Sarcina lutea & $10.0 \pm 0.58$ & $42.0 \pm 0.23$ \\
Staphylococcus aureus & $10.0 \pm 0.39$ & $42.0 \pm 0.56$ \\
Escherichia coli & $9.0 \pm 0.22$ & $42.0 \pm 0.43$ \\
Pseudomonas aeruginosa & $11.0 \pm 0.80$ & $42.0 \pm 1.11$ \\
Salmonella Typhi & $10.0 \pm 0.13$ & $45.0 \pm 0.73$ \\
S. Paratyphi & $8.0 \pm 0.38$ & $47.0 \pm 2.33$ \\
Shigella boydii & $9.0 \pm 0.81$ & $34.0 \pm 0.58$ \\
S. dysenteriae & $9.0 \pm 0.31$ & $42.0 \pm 0.22$ \\
Vibrio mimicus & $9.0 \pm 0.58$ & $40.0 \pm 0.45$ \\
V. parahaemolyticus & $9.0 \pm 0.46$ & $35.0 \pm 0.44$ \\
Candida albicans & $9.0 \pm 0.19$ & $38.0 \pm 0.49$ \\
Aspergillus niger & $10.0 \pm 0.35$ & $37.0 \pm 0.33$ \\
Saccharomyces cerevisiae & $10.0 \pm 0.21$ & $38.0 \pm 0.11$ \\
\hline
\end{tabular}

$\mathrm{CSF}=$ Chloroform soluble fraction

Cytotoxic activity of the extractives: In the brine shrimp lethality bioassay, the petroleum ether soluble fraction of $A$. chaplasha revealed the highest cytotoxic potential having $\mathrm{LC}_{50}$ value of $0.781 \pm 0.36 \mu \mathrm{g} / \mathrm{ml}$, whereas the standard vincristine sulphate exhibited an $\mathrm{LC}_{50}$ value of $0.451 \mu \mathrm{g} / \mathrm{ml}$. On the other hand, among the test samples of $B$. spectabillis, the aqueous soluble fraction displayed the highest cytotoxic potential with $\mathrm{LC}_{50}$ value $1.28 \pm 0.57 \mu \mathrm{g} / \mathrm{ml}$. This suggested the presence of potent bioactive components in the above mentioned extracts (Table 2).

\section{Conclusion}

It is clearly evident from the above findings that the leaves of A. chaplasha and B. spectabillis have potent antioxidant and cytotoxic properties. The plants also exhibited moderate to strong membrane stabilizing potential. Therefore, these plants are good candidates for further systematic, chemical and biological studies in order to isolate the active principles.

\section{Acknowledgement}

The authors wish to acknowledge the Phytochemistry Research Laboratory of State University of Bangladesh.

\section{References}

Bauer, A.W., Kirby, W.M.M., Sherris, J.C. and Turck, M. 1966. Antibiotic susceptibility testing by a standardized single disc method. Am. J. Clin. Pathol. 45, 493-496.

Brand-Williams, W., Cuvelier, M.E., Berset, C. 1995. Use of free radical method to evaluate antioxidant activity. Lebensm. Wiss. Technol. 28, 25-30.

Butler, M.S. 2005. Natural products to drugs: natural product derived compounds in clinical trials. Nat. prod. Rep. 22, 162-195.

Flora of China, 2012. http://www.floracafe.com/Search_PhotoDetails.aspx?Pho to $=$ Top\&Id $=270$

Gan, R., Kuang, L., Xu, X., Zhang, Y., Xia, E., Song, F. and $\mathrm{Li}, \mathrm{H}$. 2010. Screening of natural antioxidants from chinese medicinal plants associated with treatment of rheumatic diseases. Molecules 15, 5988-5997

Harbertson, J. and Spayd, S. 2006. Measuring phenolics in the winery. Am. J. Enol. Vitic. 57, 280-288.

Jawla, S. 2011. Hypoglycemic potential of Bougainvillea spectabillis root bark in normal and alloxan induced diabetic rats. Pharmacol. online. 3, 73-87.

Kaisar, M.A., Rahman, M.S., Rahman, M.Z., Hasan, C.M. and Rashid, M.A. 2011. A review on phytochemicals from some medicinal plants of Bangladesh. J. Phar. Nutri. Sci. 1, 87-95.

Meyer, B.N., Ferrigni, N.R., Putnam, J.E., Jacobsen, J.B., Nicholsand, D.E. and Mclaughlin, J.L. 1982. Brine shrimp; a convenient general bioassay for active plant constituents. Planta Med. 45, 31-34.

Omale, J. and Okafor, P.N. 2008. Comparative antioxidant capacity, membrane stabilization, polyphenols composition and cytotoxicity of the leaf and stem of Cissus multistriata. Afr. J. Biotechnol. 7, 3129-3133.

Prasad, S., Kashyap, R.S., Deopujari, J.Y., Purohit, H.J., Taori, G.M. and Daginawala, H.F. 2006. Development of an in vitro model to study clot lysis activity of thrombolytic drugs. Thrombosis J. 4, 14.

.Saikia, H. and Lama A. 2011. Effect of Bougainvillea spectabilis leaves on serum lipids in albino rats fed with high fat diet. Int. J. Pharm. Sci. Drug Res. 3, 141-145. 
Sikder, M.A., Rahman, M.A., Kaisar, M.A., Rahman, M.S., Hasan, C.M. and Rashid, M.A. 2011. In vitro antioxidant, reducing power, free radical scavenging and membrane stabilizing activities of seeds of Syzygium cumini L. Lat. Am. J. Pharm. 30, 781-785.
Van Wagenen, B.C., Larsen, R., Cardellina, J.H. II, Ran dazzo, D., Lidert, Z.C., and Swithenbank, C. 1993. Ulosantoin, a potent insecticide from the sponge Ulosa ruetzleri. J. Org. Chem. 58, 335-337. 